\title{
Characterization and Antimicrobial Characteristics of Chitosan Modified Hibiscus sabdariffaL.extract
}

Fatma Elzhraa Mansour

Physics Department, Faculty of Science, Mansoura University, Mansoura, 35516, Egypt

Physics Department, Faculty of Arts and Sciences AL Methnab Qassim University, Saudia Arabia

Elzahraamansour97@yahoo.com

\begin{abstract}
Samples of Chitosan (Cs) natural polymer containing successive amount of Hibiscus sabdariffaLextract were sucssesfuly synthesized using traditional simple casting route. Prepared thin films were characterized using fourier transform infrared (FTIR). FT-IR of synthesized thin films reveals maintenance of the characteristic bands of chitosan in addition to the appearance of two new sharp intense bands at 1782 and $954 \mathrm{~cm}^{-1}$ intensified with increasing plant extract content and assigned to the interaction between $\mathrm{NH} 2$ of polymer skeleton with falvanoids present in the extract. Obtained data poit out to a formation of homogenous composite structure. X-ray diffraction data (XRD) reval no prounounced band indicating the amorphous structure of synthesized final polymeric product. In vitro antimicrobial studies were performed using both gram negative and positive bacteria in addition to Fungul and Yeast activity using simple minimum inhibition zone (MIZ) standeredroutain.
\end{abstract}

Keywords: Chitosan; Hibiscus sabdariffa L.extract; FTIR; Antimicrobial Activity.

Date of Submission: 18 September, 2018

DOI: 10.24297/jap.v14i3.7778

ISSN: 2347-3487

Volume: 14 Issue: 3

Journal: Journal of Advances in Physics

Website: https://cirworld.com

This work is licensed under a Creative Commons Attribution 4.0 International License. 


\section{Introduction}

Recently biodegradable, biocompatible polymers modified with different fillers are studied by different researchers [1-3] for their versatile uses in different fields of application. Chitosan is one of the most important and low cost natural biodegradable polymers used as a carrier for pharacuticals active ingredients as stabilizing agent to enhance their characteristics.

Chitosan represent a class of linear polysaccharide prepared through acetylation process of chitin and their monomer consists of a combination of $\mathrm{N}$-acetyle-D-glucosamine (acetyled) and D-glucosamine (deacetyled) groups whose percent depends on the deactylation ratio [4]. Chitosan usually obtained from the hard outer skeleton of shellfish and owe a huge medical uses especially in the obesity and high cholesterol disease treatments [5].

Chitosan shows a promising biological activities against pathogenic grams so its film is unique in the application of food preservation through extension of time interval and reduction of the growth rate of microorganisms as reported by Han [6] in addition to their uses as chelating agent and heavy metal trapper and also in water treatment $[7,8]$.

Hibiscus sabdariffaL. usually used in foods, wines while their leaves and tender stem can be added to salads and chutney. As all plants, the compositions of Hibiscus sabdariffaL, contains polyphenolic acids, flavonoids, and anthocyanins [9] which owes as manymedicinal applications including treatment of hypertension, pyrexia, liver damage and leukaemia due to its high content of protocatechuic acid [10].In addition to these characteristics Hibiscus sabdariffaL. extract can also usedas an antioxidant for protection against low density lipoprotein (LDL)-oxidation and has hypolipidemic effects in vivo [11].

Present work aims to evaluate the role of Hibiscus sabdariffa $L$. addatives for anatural degradable polymer (chitosan) in the antimicrobial activity and to correlate change in the activity index with the concentration and type of interaction between composite constituent material.

\section{Materials and Methods}

Chitosan of low molecular weight supplied by Sigma Aldrich Co. Hibiscus sabdariffa L. obtained from Egyptian markets. The studied pristinechitosan thin films and other samples containing successive amount of plant extract were synthesized via casting technique with labled in Table (1). Bi-distiled water containing $2 \%$ acetic acid were used a common solvent. Starting materials was vigorously stirred at room temperature until a clear transparent viscous liquid is obtaine. Calculated amounts of extract were added to the polymer solution and poured in a plastic Petri dishes. Dishes are incubated in an oven at $50^{\circ}$ up to two days for drying. Obtained films was peeled from the Petri dishes and kept in desiccator until use.

Table (1) Sample notation and composition

\begin{tabular}{|c|c|c|c|c|c|c|c|}
\hline Sample & Cs & H1 & H2 & H3 & H4 & H5 & H6 \\
\hline Chitosan & 100 & 99 & 98 & 97 & 96 & 95 & 94 \\
\hline Extract ml added & 0 & 1 & 2 & 3 & 4 & 5 & 6 \\
\hline
\end{tabular}

XRD diffraction (XRD) was used to identifythe degree of crystallinity throughout the samples and to investigate complexation behavior between polymeric matrices and Hibiscus sabdariffaL..XRD diffraction data plotted as Bragg's angle (20) versus intensity using PANalyticalX'Pert PRO adopting Cu Katargetusing wavelength $\lambda=1.540 \AA$ and tube operating at $45 \mathrm{kV}-40 \mathrm{~mA}$ within the Bragg's angle (20) ranging between $5^{\circ}$ $80^{\circ}$. FT-IR spectral data collected using Nicolet iS10 spectrophotometer adopted 32 runs at room temperature 
within the spectral range $4000-400 \mathrm{~cm}^{-1}$. UV/vis. spectral data collected using Jasco 570 double beam spectrometer within the range $190-650 \mathrm{~nm}$.

Biological activities were evaluated against Candida albicans fungi, Pseudomonas aeuroginosa, Escherichia coli gram negative bacteria and Bacillus subtilis, Staphylococcus aureusgram positive bacteria via minimum inhibition zone (MIZ) route previously discuused [12].Antibacterial activity of a known standard antibiotic (ampicillin) and antifungal (Colitrimazole) was also measured to calculate the percent activity index of synthesized samples using the formula:

$$
\% \text { Activity Index }=\frac{\text { Zone of inhibition by test compound (diametre) }}{\text { Zone of inhibition by standard (diametre) }} \times 100
$$

\section{Results and Discussion}

\section{X-ray diffraction data}

X-ray diffraction experimental data measured in the Bragg angle (20) range $5-80^{\circ}$ shown in Figure (1) reveals the presence of a single hump at about $20^{\circ}$ characterized the amorphous nature of prepared thin films. It was notices also that the intensity of this hump decreases with increasing filler content indicating an increase of the amorphous nature of prepared film with increasing Hibiscus sabdariffa $L$. extract content and pointing to the homogeneity and complexation behaviour between the two component.

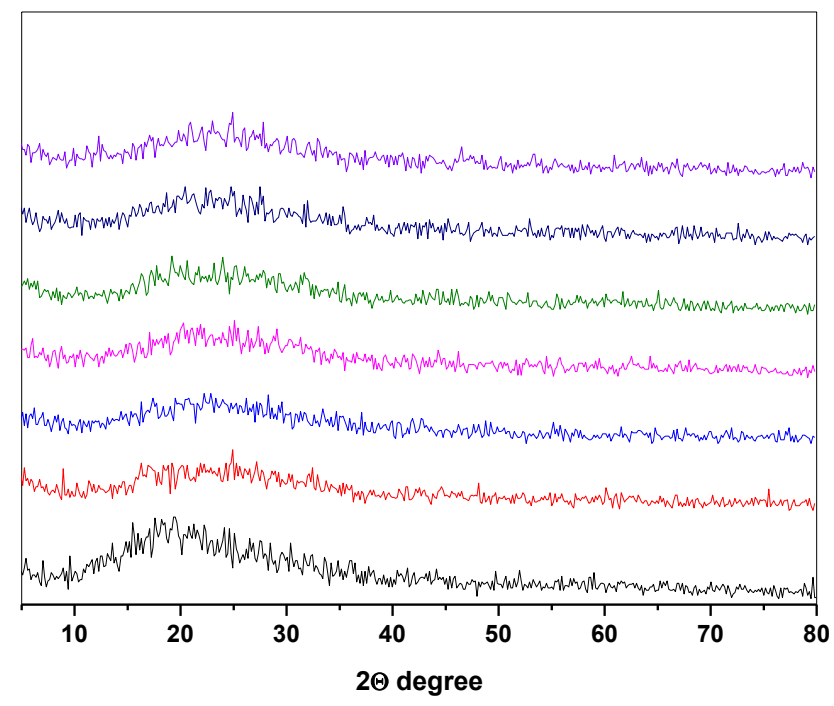

Figure (1): XRD spectra of pure and doped chitosan samples

\section{FTIR Absorption Spectra}

FTIR Spectrum of Hibiscus extract Figure (2) revels the presence of many bands characterize several plant extract including a broad band located between $3350-3500 \mathrm{~cm}^{-1}$ assigned for water molecule or $\mathrm{OH}$ bond,. A sharp intense band observed at about 1180 and $2360 \mathrm{~cm}^{-1}$ related to double bond $\mathrm{C}=\mathrm{C}$ and $\mathrm{C}-\mathrm{H}$ of the aromatic ring respectively. In addition, the band of carbonyl group located at about $1782 \mathrm{~cm}^{-1}$ was also observed combined with that of ether group at about $1070 \mathrm{~cm}^{-1}$. Such bands characterize flavonoid compounds in Hibiscus sabdariffa L. havingthe chemical structure shown in Figure (3). 


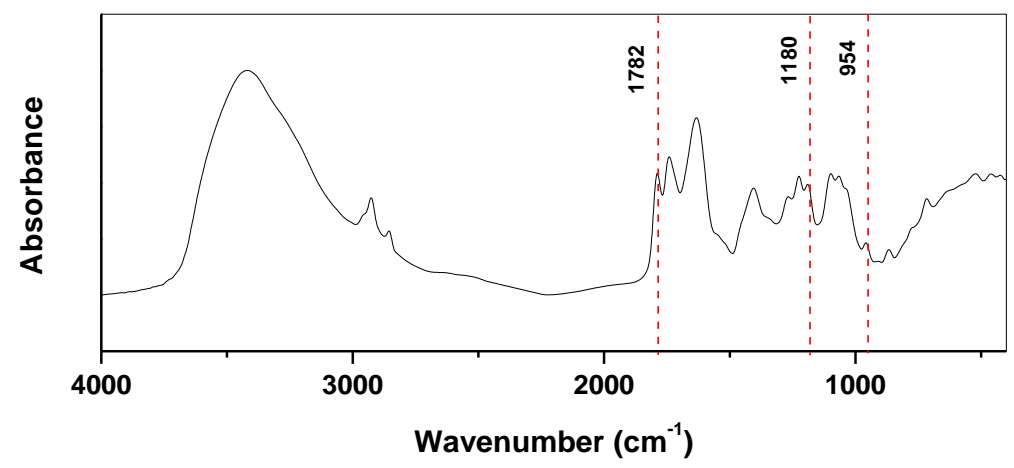

Figure (2) FT-IR spectrum of Hibiscus sabdariffa L.extract<smiles></smiles>

Figure (3) Functional groups in the structure of flavonoids

Chitosan represents a class of natural polymers that are mainly consists three functional groups, amino grous, primary and secondary alcohol. Figure (3) indicates FTIR spectral data of pure chitosan and other samples that contain variable amounts of the Hibiscus extract. All samples show the maintenance of the main constituent material (chitosan) with an obvious change in peak position and intensity with increasing filler content indicating notable change in their physicochemical characteristics. Table (2) list the observed band position and their assignments.

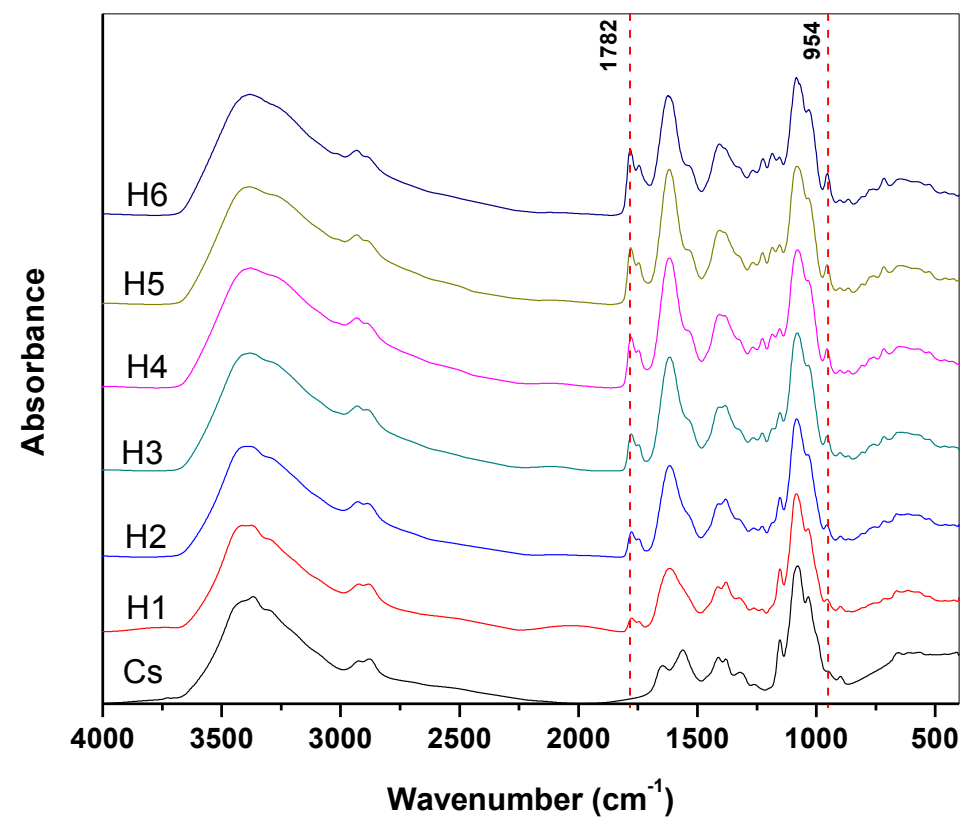

Figure (4): FTIR optical absorption spectra of pure and doped chitosan samples 
Table (2): FTIR band assignment and peak position for pure chitosan

\begin{tabular}{|c|c|c|}
\hline Wavenumber $\left(\mathrm{cm}^{-1}\right)$ & Band assignment & Reference \\
\hline $3000-3500$ & Stretching vibration of $(\mathrm{O}-\mathrm{H})$ overlapped with $(\mathrm{N}-\mathrm{H})$ & \\
\hline 2927-2882 & Asymmetric stretching vibration of aliphatic $\mathrm{CH}, \mathrm{CH} 2$ and $\mathrm{CH} 3$ & \\
\hline 1665 & $\mathrm{C}=\mathrm{O}$ bond stretching & \\
\hline 1561 & $\mathrm{~N}-\mathrm{H}$ stretching of amide II & \\
\hline 1411 & Bend vibration of $\mathrm{OH}$ and $\mathrm{CH}$ & \\
\hline 1342 & Amide III (NH3) & \\
\hline $1151,1081,1034$ and 656 & Characteristic to saccharide structure & \\
\hline
\end{tabular}

\section{Antibacterial Studies}

In vitro antimicrobial studies were performed using both gram negative and positive bacteria in addition to Yeast activity using simple minimum inhibition zone (MIZ) standered routain. Biological activities were evaluated against Pseudomonas aeuroginosa, Escherichia coli gram negative bacteria and Bacillus subtilis, Staphylococcus aureusgram positive bacteria in addition to Candida albicans yeast. Obtained data was also compared with a standard antibiotic to calculate the activity index.

Table (3) shows the variation of diameter zone and calculated activity index with pristine sample of chitosan (Cs) and samples of chitosan containing different amount of Hibiscus sabdariffa L.. It was observed that increasing of Hibiscus sabdariffa $L$. content result in increase of the diameter zone and activity index in all cases as shown in Figure (5). Such effect can be attributed to the presence of $\mathrm{OH}$ group in the falvonoids structure (Figure 2) which may react with free ions released during the interaction between $\mathrm{NH}_{2}$ group of chitosan and other constituent of the extract.

Tablee (3) Diameter of inhibition zone and activity index of tested samples

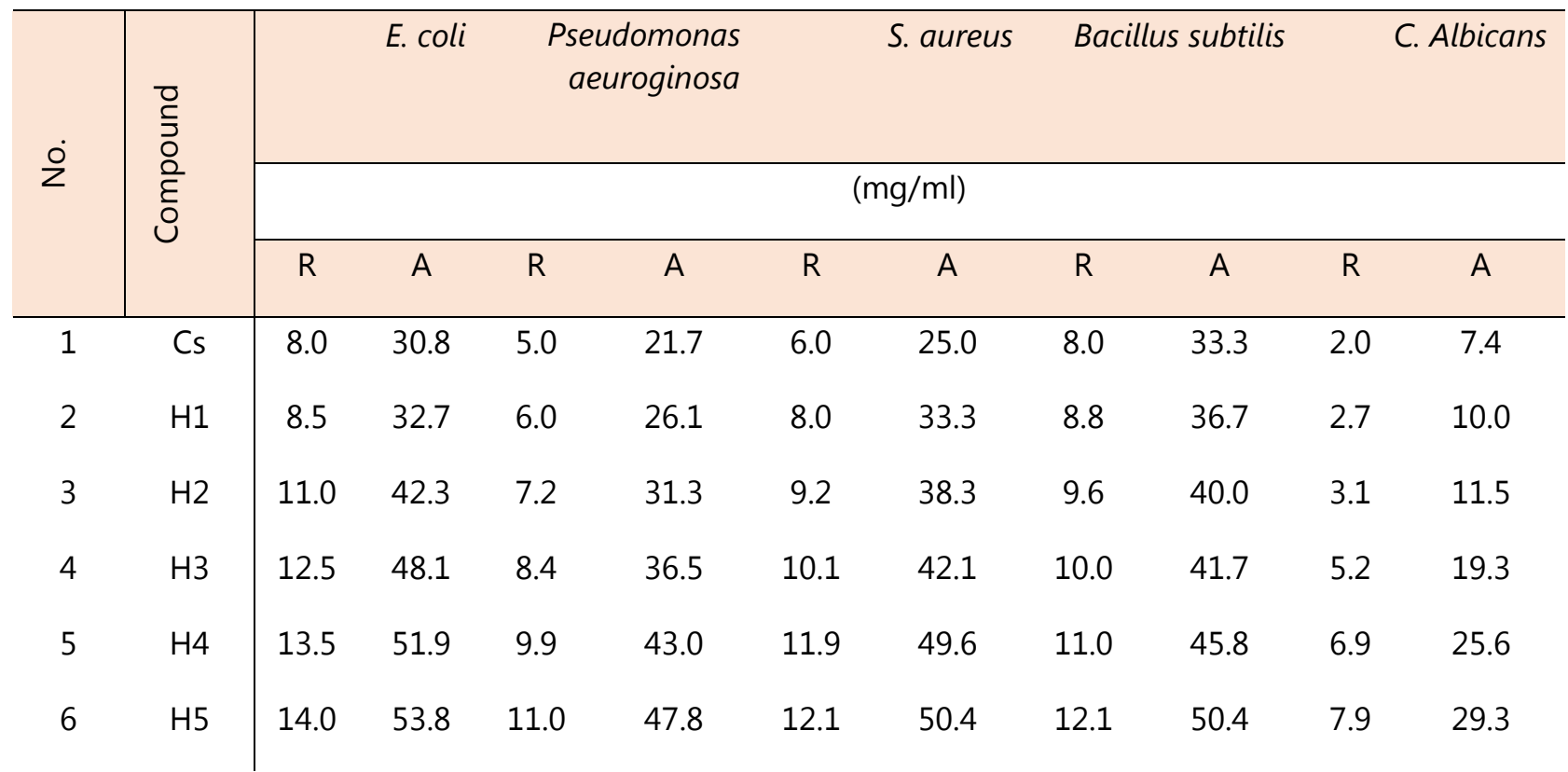




\begin{tabular}{|c|c|c|c|c|c|c|c|c|c|c|}
\hline $\mathrm{H} 6$ & 15.5 & 59.6 & 12.6 & 54.8 & 14.6 & 60.8 & 14.2 & 59.2 & 9.2 & 34.1 \\
\hline Ampicillin & 26 & 100 & 23 & 100 & 24 & 100 & 24 & 100 & --- & NA \\
\hline Colitrimazole & NA & ---- & NA & ---- & NA & ---- & NA & ---- & 27 & 100 \\
\hline
\end{tabular}

\section{R Diameter of inhibition zone (mm), A Activity index \%}

Figure (5) represent a bar representation the in vitro activity index test for a different pathogenic grams and Yeast. It was obvious that the activity index generally increases with increasing concentration of the extract. It was also clear that $\mathrm{E}$-Coli and $\mathrm{S}$. arures are most effected by the extract concentration while P. aeuroginosa nd C. Albicans is the lowst.

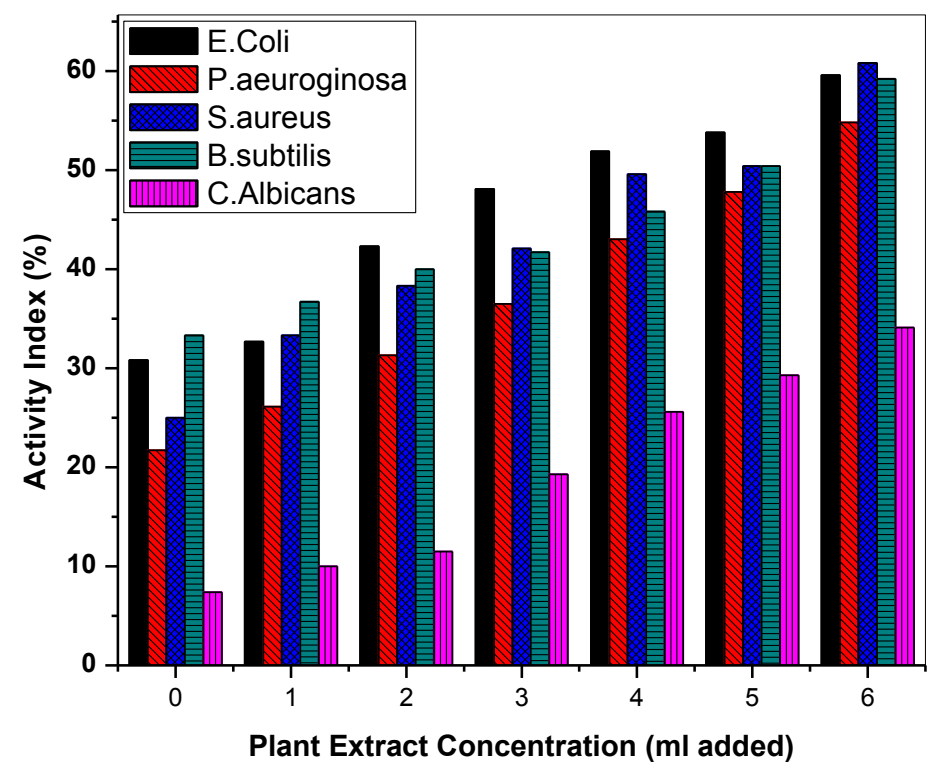

Figure (5): Activity index as a function of Hibiscus sabdariffa L. content

\section{Conclusions}

Chitosan doped Hibiscus sabdariffa L extract were preperead via traditional solution casting route. FT-IR of synthesized reveals maintenance of the characteristic bands in addition to the appearance of two new bands at 1782 and $954 \mathrm{~cm}^{-1}$ whose intensity increases with further addition of plant extract indicating a formation of new vibrational mode resulting from interaction between $\mathrm{NH} 2$ of polymer skeleton with falvanoids present in the extract. All samples were tested for their in vitro antimicrobial behavior, their activity index calculated and compared to a standared drug via simple minimum inhibition zone (MIZ) standered routain. It was observed that increasing of Hibiscus sabdariffa L. content result in increase of the diameter zone and activity index in all cases as shown in Figure (5). Such effect can be attributed to the presence of $\mathrm{OH}$ group in the falvonoids structure which may react with free ions released during the interaction between $\mathrm{NH}_{2}$ group of chitosan and other constituent of the extract. 


\section{References}

1. N.G. Shimpi, Biodegradable and Biocompatible Polymer Composites Processing, Properties and Applications, Woodhead Publishing, 2018.

2. T.F. Garrison, A. Murawski, R.L. Quirino, Bio-Based Polymers with Potential for Biodegradability, Polymers 8(2016)262.

3. A. M. Abdelghany, M. S. Meikhail, G. E. A. Abdelraheem, S. I. Badr, N. Elsheshtawy, Lepidium sativum natural seed plant extract in the structural and physical characteristics of polyvinyl alcohol, International Journal of Environmental Studies, https://doi.org/10.1080/00207233.2018.1479564.

4. E. Sogut, A.C. Seydim, Development of Chitosan and Polycaprolactone based active bilayer films enhanced with nanocellulose and grape seed extract, Carbohydrate Polymers, 195(2018)180.

5. K. Halász, L. Csóka, Black chokeberry (Aronia melanocarpa) pomace extract immobilized in chitosan for colorimetric pH indicator film application, Food Packaging and Shelf Life, 16(2018)185.

6. J.H. Han, Antimicrobial food packaging, Food Technology, 54(2000)56.

7. Y.G. Abou El-Reash, A.M. Abdelghany, A. Abd Elrazak, Removal and Separation of Cu(II) from Aqueous Solutions Using Nano-Silver Chitosan/Polyacrylamide Membranes, International Journal of Biological Macromolecules, 86(2016)798.

8. Y.G. Abou El-Reash, A.M. Abdelghany, K. Lepold, Solid phase extraction of $\mathrm{Cu}^{2+}$ and $\mathrm{Pb}^{2+}$ from waters using new thermally treated Chitosan/ Polyacrylamide thin films; Adsorption kinetics and thermodynamics, International Journal of Environmental Analytical Chemistry, 97(10(2017)965-982.

9. $\quad$ C.C. Chen, J.D. Hsu, S.F. Wang, J. Agric. Food Chem. 51(2003)5472.

10. N.M. Esa, F.S. Hern, A. Ismail, C.L. Yee, Food Chemistry, 122(2010)1055.

11. V. Prasongwatana, S. Woottisin, P. Sriboonlue, V. Kukongviriyapan, J. of Ethnopharmacology, 117(2008) 491

12. M. S. Meikhail, A. M. Abdelghany, W. M. Awad, Role of CdSe quantum dots in the structure and antibacterial activity of chitosan/poly $\varepsilon$-caprolactone thin films, Egyptian Journal of Basic and Applied Sciences, 5(2)(2018)138. 